\title{
Auteur, traducteur, collaborateur, imprimeur... qui écrit?, sous la direction de Martine Furno et Raphaële Mouren
}

\section{Maurizio Busca}

\section{(2) OpenEdition}

\section{Journals}

\section{Edizione digitale}

URL: http://journals.openedition.org/studifrancesi/2114

DOI: $10.4000 /$ studifrancesi. 2114

ISSN: 2421-5856

\section{Editore}

Rosenberg \& Sellier

\section{Edizione cartacea}

Data di pubblicazione: 1 aprile 2014

Paginazione: 131-132

ISSN: 0039-2944

\section{Notizia bibliografica digitale}

Maurizio Busca, «Auteur, traducteur, collaborateur, imprimeur... qui écrit?, sous la direction de Martine Furno et Raphaële Mouren », Studi Francesi [Online], 172 (LVIII | I) | 2014, online dal 01 avril 2014, consultato il 18 septembre 2020. URL : http://journals.openedition.org/studifrancesi/2114 ; DOI : https://doi.org/10.4000/studifrancesi.2114

Questo documento è stato generato automaticamente il 18 settembre 2020.

\section{cc) (†) $\odot$}

Studi Francesi è distribuita con Licenza Creative Commons Attribuzione - Non commerciale - Non opere derivate 4.0 Internazionale. 


\title{
Auteur, traducteur, collaborateur, imprimeur... qui écrit?, sous la direction de Martine Furno et Raphaële Mouren
}

\author{
Maurizio Busca
}

\section{NOTIZIA}

AA. VV., Auteur, traducteur, collaborateur, imprimeur... qui écrit?, sous la direction de Martine FURNo et Raphaële MOUREN, Paris, Classiques Garnier, 2012 («Études et essais sur la Renaissance», 99), pp. 329.

1 La presente miscellanea costituisce una sorta di prolungamento del convegno tenutosi nel 2006 a Grenoble Qui écrit? Figures de l'auteur et des co-élaborateurs du texte. Oggetto dei dodici saggi che compongono la raccolta sono le figures discrètes della produzione libraria del Cinquecento: personalità il cui ruolo è stato determinante per l'elaborazione di testi a stampa, per la loro pubblicazione o ancora per la loro diffusione, ma che la storia ha spesso dimenticato e la critica trascurato.

Il volume, che si apre con una Introduction redatta dalle due curatrici (pp. 7-9), si divide in quattro sezioni e raccoglie i contributi seguenti: Prima parte (Du poids de l'éditeur: un exemple au dix-septième siècle): Anne cayuela, Alonso Pérez: un demi-siècle de passions éditoriales, pp. 13-32. Seconda parte (Incertitudes auctoriales et mains multiples): Malcolm WALSBY, L'auteur, l'imprimeur et l'imprimé polémique et éphémère français au seizième siècle, pp. 35-55; Ginette VAGENHEIM, Qui a écrit les "antichità romane» attribuées à Pirro Ligorio (1512-1583)?, pp. 57-68; Alexandre VANAUTGAERDEN, Érasme à Venise, pp. 69-116. Terza parte (Silhouettes de traducteurs): Isabelle DIU, Identification du traducteur humaniste. L'exemple d'Érasme, traducteur de grec en latin, pp. 119-137; Philip FORD, Traductions en vers de l'Iliade au seizième siècle, pp. 139-163; Michèle CLÉMENT, Mettre en vers français une 
poétesse latine. Proba Falconia à Lyon en 1557, pp. 165-202; Mathilde THOREL, Discours et silences du paratexte. Aspects de l'auctorialité dans les traductions de langue vulgaire avant 1540, pp. 203-217. Quarta parte (Livres anciens et éditions modernes): Raphaële MOUREN, Réflexions historiographiques et méthodologiques sur les éditions savantes, pp. 221-236; Tristan vigliano, Le De disciplinis de Vivès, de l'édition princeps à l'édition critique, pp. 237-265; Christine BÉNÉVENT, Érasme et ses «contrefacteurs», pp. 267-300; Jean-Eudes GIROT, Comment éditer Muret à l'époque moderne, pp. 301-316.

3 Le prime tre sezioni sono dedicate a diverse figure di collaboratori, traduttori, editori e stampatori, mentre l'ultima sezione affronta questioni di carattere metodologico concernenti le problematiche con le quali il ricercatore si deve confrontare per produrre un'edizione moderna di opere stampate in un'epoca in cui i ruoli di letterati, manuali e antiquari si avvicinano e talora si sovrappongono. 